\title{
Níveis de fósforo disponível em dietas para codornas japonesas de 45 a 57 semanas de idade
}

\author{
Carlos Henrique Rocha Costa ${ }^{1}$, Sergio Luiz de Toledo Barreto², Paulo Cezar Gomes², Lúcia \\ Heiko Hosoda ${ }^{3}$, Carolina Abe Lipari ${ }^{3}$, Heder José D'Avila Lima ${ }^{4}$
}

1 Doutorando em Zootecnia - Departamento de Zootecnia/Universidade Federal de Viçosa.
2 Departamento de Zootecnia/Universidade Federal de Viçosa.
${ }^{3}$ Graduando em Zootecnia - Departamento de Zootenia/Universidade Federal de Viçosa.
${ }^{4}$ Mestrando em Zootecnia - Departamento de Zootecnia/Universidade Federal de Viçosa.

RESUMO - Conduziu-se um experimento com o objetivo de verificar o efeito de níveis de fósforo disponível (Pd) na dieta sobre o desempenho, a qualidade dos ovos, o tecido ósseo e as porcentagens de fósforo (P), cálcio (Ca) e magnésio (Mg) nas excretas produzidas por codornas durante o terço final de postura. Foram utilizadas 300 codornas japonesas com 313 dias de idade, distribuídas em 30 unidades experimentais de dez aves. O delineamento foi inteiramente casualizado, composto de cinco níveis de $\mathrm{Pd}(0,15 ; 0,25 ; 0,35 ; 0,45$ e 0,55\%), com seis repetições por tratamento. As dietas experimentais foram isoproteicas (20,0\% PB), isocalóricas (2.900 kcal EM/kg), isocálcicas (3,0\% Ca) e isoaminoacídicas. O aumento dos níveis de Pd na dieta aumentou linearmente os teores de Ca e Mg na tíbia, entretanto reduziu linearmente a altura dos ovos analisados. Observou-se efeito quadrático sobre o peso específico, o peso e a porcentagem de casca, a porcentagem de cálcio na casca e de fósforo na tíbia, cujos pontos de máxima foram atingidos com a utilização de 0,43; 0,41; 0,42; 0,27 e 0,42\% $\mathrm{Pd}$, respectivamente. Efeitos quadráticos também foram observados para excreção de Ca, cinzas e P, cujos valores máximos foram obtidos com a utilização de 0,34; 0,30 e 0,43\% Pd na dieta, respectivamente. Nos demais parâmetros avaliados, não houve efeito dos níveis de Pd. Dietas contendo 0,15\% Pd atendem satisfatoriamente às exigências para desempenho e manutenção da integridade física do ovo, além de reduzir a excreção de fósforo sem provocar perda de ovos por problemas de casca nem ocorrência de fadiga de gaiola por enfraquecimento do sistema ósseo, embora seja observada redução na mineralização da casca e do tecido ósseo de codornas japonesas no terço final do ciclo de produção (45 a 57 semanas de idade).

Palavras-chave: Coturnix coturnix japonica, desempenho produtivo, qualidade do ovo, tecido ósseo

\section{Available phosphorus levels for Japanese quail diets from 45 to 57 weeks of age}

\begin{abstract}
An experiment was conducted aiming to verify the effect of different levels of available phosphorus (AP) in the diet on performance, egg quality, bone tissue and percentages of $\mathrm{P}, \mathrm{Ca}$ and $\mathrm{Mg}$ in excreta produced by quails during the final third of the production cycle. A total of 300 Japanese quails, with 313 days of age, was assigned to 30 experimental units of ten birds. A completely randomized design was used, with five levels of AP $(0.15,0.25,0.35,0.45$ and $0.55 \%)$, with six replicates per treatments. The experimental diets were isoproteic (20.0\% CP), isocaloric (2.900 kcal ME/kg), isocalcium (3.0\% Ca) and isoaminoacidic. The increasing levels of AP in the diet linearly increased the concentration of $\mathrm{Ca}$ and $\mathrm{Mg}$ in the tibia; however, it linearly reduced the height of eggs analyzed. There was quadratic effect for specific gravity, weight and shell percentage, shell percentage of $\mathrm{Ca}$ and $\mathrm{P}$ in the tibia, achieving maximum points with the use of 0.43 , 0.41 , 0.42, 0.27 and $0.42 \%$ AP, respectively. Quadratic effects were also observed for excretion of Ca, P and ash, yielding maximum values with the use of $0.34,0.30$ and $0.43 \%$ AP in the diet. For other parameters, there was no effect of dietary phosphorus. Diet containing $0.15 \%$ AP satisfactorily meets the performance and maintenance of the physical integrity of the egg, in addition to reducing $\mathrm{P}$ excretion, without any loss caused by problems with egg shell nor occurrence of cage fatigue by weakening of the bone system, although there is reduction in the mineralization of the shell and bone tissue of Japanese quail in the final third of the production cycle (45 to 57 weeks of age).
\end{abstract}

Key Words: bone tissue, Coturnix coturnix japonica, egg quality, productive performance

Recebido em 12/11/2009 e aprovado e m 24/11/2010. 


\section{Introdução}

No Brasil, a criação de codornas japonesas (Coturnix coturnix japonica) tem crescido principalmente nas regiões Sul e Sudeste. Mesmo assim, ainda são poucas as informações disponíveis na literatura nacional sobre a nutrição dessas aves. Grande parte das pesquisas científicas envolvendo os níveis nutricionais e o desempenho de codornas refere-se a dados obtidos em outros países onde as linhagens utilizadas, as condições ambientais e o manejo diferem daqueles existentes em nosso país.

Na formulação de rações para codornas, são comumente utilizadas tabelas de exigências nutricionais confeccionadas em outros países (Recomendação..., 1987; Nutrient..., 1994). Ao analisar essas tabelas, observa-se que não há uniformidade na determinação dos períodos referidos para a fase inicial e de crescimento nem ao menos para os níveis nutricionais recomendados para a fase inicial e final de produção de ovos.

No NRC (1994), as exigências nutricionais de codornas japonesas são citadas sem precisar, entretanto, o término do período de crescimento, ao passo que na (Recomendação..., 1987), existe uma divisão da fase inicial de criação em períodos de 0 a 3 e de 4 a 7 semanas. Ambas as tabelas referem-se às exigências nutricionais na fase de produção em apenas uma fase para todo o período de produção. Não obstante, as recomendações de fósforo (P) presentes na Recomendação... (1987) são substancialmente mais elevadas que as do NRC (1994), em que a exigência é de 0,35\% de fósforo disponível (Pd) para codornas em produção, em dietas com $2.900 \mathrm{kcal}$ de EM/kg e 20\% de proteína bruta. Costa et al. (2007) recomendam 0,31\% de Pd em dietas com os mesmos teores energéticos e proteicos para codornas japonesas de 61 a 145 dias de idade.

Com o avançar dos anos, as aves ficaram mais pesadas, mais produtivas, com ovos maiores e maior resistência, a julgar pelas informações de campo sobre as atuais taxas de mortalidade (Oliveira, 2007). Contudo, o consumo dessas aves também aumentou um pouco, sendo as recomendações para a fase de postura dessas aves todas baseadas na fase inicial e pico de postura. Portanto, decidiu-se verificar se essas recomendações sofrem ou não alteração no terço final do ciclo de postura. Com base nos resultados encontrados, será possível ter uma ideia da real necessidade e da eficiência dessas aves em utilizarem o fósforo frente a uma menor produção, o que gerará dados de pesquisas nacionais para que se possa obter considerável rendimento produtivo e econômico desta espécie, pelos produtores, nesta fase. Como o fósforo é o mineral que mais encarece a ração, é importante estudar a manutenção ou não de sua exigência inicial, também durante o pós-pico de postura. Também é importante ressaltar que, pouco destaque é dado a esse mineral, que é um elemento indispensável na vida das aves, durante a fase de crescimento e de produção, por participar da formação do esqueleto e contribuir para a formação da casca do ovo.

Assim como o fósforo, o magnésio também têm grande importância na formação da casca do ovo, sendo que a conversão de $25-\mathrm{OHD}_{3}$ em $1,25(\mathrm{OH})_{2} \mathrm{D}_{3}$ é dependente do adequado nível e disponibilidade desse mineral. Além disso, o cálcio e o magnésio podem combinar com o fosfato transformando-o numa forma insolúvel, interferindo na absorção do fósforo.

Objetivou-se neste trabalho determinar o nível de Pd na dieta, que proporcione desempenho produtivo, qualidade da casca dos ovos e status nutricional do tecido ósseo satisfatórios de codornas japonesas no terço final do ciclo de produção.

\section{Material e Métodos}

O experimento foi realizado no setor de Avicultura do Departamento de Zootecnia da Universidade Federal de Viçosa, Minas Gerais. Foram utilizadas 300 codornas japonesas (Coturnix coturnix japonica), em terço final de postura, com 313 dias de idade, durante os quatro períodos experimentais de 21 dias.

As aves foram alojadas em gaiolas de arame galvanizado, com dimensões de $100 \times 23 \times 20 \mathrm{~cm}$ (comprimento $\times$ largura $\times$ altura), dispostas em três andares, montadas em esquema de escada. Cada gaiola foi subdividida em duas repartições iguais de $50 \mathrm{~cm}$, cada uma com capacidade para dez aves, fornecendo uma área de $115 \mathrm{~cm}^{2} /$ ave. Sobre o piso de cimento, abaixo das gaiolas, foi colocada uma camada de maravalha para absorver o excesso de umidade das excretas. O comedouro e o bebedouro eram do tipo calha, em chapa metálica galvanizada, ambos percorrendo toda a extensão das gaiolas, sendo o comedouro na parte frontal e o bebedouro na parte posterior da gaiola.

Três dias antes do início do período experimental, as aves foram uniformizadas pela postura e pelo peso corporal, causando menor estresse às aves.

O delineamento experimental adotado foi inteiramente ao acaso, sendo constituído por cinco tratamentos (cinco níveis de Pd na dieta), com seis repetições e dez aves por unidade experimental. Foram formuladas cinco dietas experimentais, isonutritivas, exceto para os níveis de fósforo total e disponível, à base de milho e farelo de soja, com cinco 
níveis $(0,15 ; 0,25 ; 0,35 ; 0,45$ e $0,55 \%)$ de Pd, constituindo-se os tratamentos experimentais (Tabela 1 ).

As dietas foram formuladas para atender às exigências nutricionais de codornas no terço final do ciclo de produção, seguindo as recomendações preconizadas pelo NRC (1994), exceto para as exigências de metionina + cistina digestíveis e lisina digestível, treonina digestível, triptofano digestível e de cálcio, que foram baseadas nas recomendações de Pinto et al. (2003 a,b), Umigi et al. (2007), Pinheiro et al. (2008) e Shrivastav \& Panda (1999), respectivamente.

Água e ração foram fornecidas à vontade ao longo de todo o período experimental. As temperaturas $\left({ }^{\circ} \mathrm{C}\right)$ e a umidade relativa (\%) foram monitoradas duas vezes ao dia, às 8 h e às $16 \mathrm{~h}$, por meio de termômetros de máxima e mínima e de bulbo seco e bulbo úmido posicionados em pontos estratégicos no galpão.
As aves utilizadas no experimento já haviam ultrapassado o pico de postura e continuaram recebendo 17 horas de luz diária até o término do experimento.

O parâmetro de desempenho foi avaliado pela produção média de ovos por ave-dia (\%) e por ave-alojada (\%), peso médio dos ovos (g), massa de ovos (g), consumo de ração (g de ração/ave-dia), conversão alimentar (g de ração por dúzia e por massa de ovos), ganho de peso (g) e viabilidade (\%).

Para o parâmetro de qualidade dos ovos, avaliaram-se a produção de ovos viáveis para comercialização ((nº total de ovos viáveis produzidos por UE)/(nº total de ovos produzidos $) \times 100$ ) e produção de ovos viáveis por ave-dia ((taxa de postura $(\%) \times$ total de ovos viáveis) $/\left(n^{\circ}\right.$ total de ovos produzidos)), o peso específico $\left(\mathrm{g} / \mathrm{cm}^{3}\right)$, o peso de casca (g), a porcentagem de casca (\%), o peso de albúmem (g), a porcentagem de albúmem (\%), o peso de gema (g), a

Tabela 1 - Composição percentual das dietas para codorna japonesa na fase de postura (com base na matéria natural)

\begin{tabular}{|c|c|c|c|c|c|}
\hline \multirow[t]{2}{*}{ Ingrediente } & \multicolumn{5}{|c|}{ Nível de fósforo disponível (\%) } \\
\hline & 0,15 & 0,25 & 0,35 & 0,45 & 0,55 \\
\hline Milho & 51,140 & 51,140 & 51,140 & 51,140 & 51,140 \\
\hline Óleo de soja & 4,387 & 4,387 & 4,387 & 4,387 & 4,387 \\
\hline Calcário & 7,395 & 7,050 & 6,705 & 6,360 & 6,015 \\
\hline Fosfato bicálcico & 0,251 & 0,791 & 1,332 & 1,873 & 2,413 \\
\hline Sal comum & 0,335 & 0,335 & 0,335 & 0,335 & 0,335 \\
\hline L-treonina $(98 \%)$ & 0,047 & 0,047 & 0,047 & 0,047 & 0,047 \\
\hline Cloreto de colina $(60 \%)$ & 0,100 & 0,100 & 0,100 & 0,100 & 0,100 \\
\hline Mistura vitamínica ${ }^{1}$ & 0,100 & 0,100 & 0,100 & 0,100 & 0,100 \\
\hline Mistura mineral $^{2}$ & 0,050 & 0,050 & 0,050 & 0,050 & 0,050 \\
\hline Antioxidante ${ }^{3}$ & 0,010 & 0,010 & 0,010 & 0,010 & 0,010 \\
\hline Surmax $100^{4}$ & 0,010 & 0,010 & 0,010 & 0,010 & 0,010 \\
\hline Energia metabolizável (kcal/kg) & 2.900 & 2.900 & 2.900 & 2.900 & 2.900 \\
\hline Proteína bruta $(\%)$ & 20,00 & 20,00 & 20,00 & 20,00 & 20,00 \\
\hline Lisina total $(\%)$ & 1,209 & 1,209 & 1,209 & 1,209 & 1,209 \\
\hline Lisina digestível (\%) & 1,117 & 1,117 & 1,117 & 1,117 & 1,117 \\
\hline Metionina + cistina total (\%) & 0,968 & 0,968 & 0,968 & 0,968 & 0,968 \\
\hline Metionina + cistina digestível (\%) & 0,894 & 0,894 & 0,894 & 0,894 & 0,894 \\
\hline Treonina total $(\%)$ & 0,783 & 0,783 & 0,783 & 0,783 & 0,783 \\
\hline Treonina digestível (\%) & 0,730 & 0,730 & 0,730 & 0,730 & 0,730 \\
\hline Triptofano total (\%) & 0,252 & 0,252 & 0,252 & 0,252 & 0,252 \\
\hline Triptofano digestível (\%) & 0,227 & 0,227 & 0,227 & 0,227 & 0,227 \\
\hline Fibra bruta (\%) & 2,768 & 2,768 & 2,768 & 2,768 & 2,768 \\
\hline Cálcio (\%) & 3,0 & 3,0 & 3,0 & 3,0 & 3,0 \\
\hline Fósforo total (\%) & 0,35 & 0,45 & 0,55 & 0,65 & 0,75 \\
\hline
\end{tabular}


porcentagem de gema (\%), a altura e o diâmetro dos ovos (mm) e os teores de cálcio, fósforo, magnésio e cinzas (\%) na casca dos ovos.

O peso específico dos ovos foi determinado pelo método de flutuação salina, conforme metodologia descrita por Hamilton (1982). Aos 16, 17 e 18음 dias de cada um dos quatro períodos experimentais de 21 dias, todos os ovos íntegros coletados foram imersos em soluções de $\mathrm{NaCl}$ com densidade variando de 1,055 a $1,100 \mathrm{~g} / \mathrm{cm}^{3}$, com intervalos de $0,005 \mathrm{~g} / \mathrm{cm}^{3}$ entre elas, totalizando dez soluções, sendo o peso específico medido por meio de um densímetro.

Quatro ovos de cada unidade experimental foram coletados aleatoriamente durante o 19, 20 e 21ํㅡㅁias de cada período, e pesados individualmente em balança com precisão de 0,001 g. Após as pesagens, foram identificados e posteriormente quebrados. A gema de cada ovo foi pesada e a respectiva casca, lavada e seca ao ar para obtenção de seu peso e, por diferença, obteve-se o peso do albúmen.

Também foram avaliados os teores de cálcio, fósforo, magnésio e cinzas na tíbia e nas excretas das aves. No final do experimento, todas as aves de cada unidade experimental foram pesadas e, dentro de cada repetição, escolheram-se quatro aves com o peso corporal o mais próximo do peso médio de sua unidade experimental, dando-se início a um novo período de coleta de dados, que teve duração de cinco dias, sendo um dia para o descanso e adaptação das aves à nova organização social dentro das instalações e quatro dias para coleta total das excretas. As dietas experimentais foram mantidas (Tabela 1 ).

A coleta total das excretas foi realizada duas vezes ao dia, às 8 e $17 \mathrm{~h}$, para evitar a fermentação. As bandejas foram encapadas com plástico para facilitar a coleta e evitar perdas do material excretado. Ao final de cada coleta, as excretas foram acondicionadas em sacos plásticos, previamente identificados e colocadas em freezer. Posteriormente, as excretas foram descongeladas, pesadas e homogeneizadas, sendo retiradas alíquotas de cada repetição para pré-secagem e colocadas em estufa de ventilação forçada a $55^{\circ} \mathrm{C}$ por um período de 72 horas. As amostras de excretas foram, então, moídas e submetidas a análises para determinação dos teores de matéria seca (MS), matéria mineral (MM), fósforo (P), cálcio (Ca) e magnésio (Mg), segundo metodologias descritas por Silva (1998).

Com o término da coleta total de excretas, todas as aves foram abatidas (120 aves), correspondendo a quatro aves por unidade experimental, para determinação do conteúdo de fósforo, cálcio, magnésio e cinzas nas tíbias.

A análise de variância foi realizada a 5\% de probabilidade utilizando-se o Programa SAEG - Sistema para Análises Estatísticas e Genética - UFV (2004). Posteriormente, os efeitos dos níveis de Pd foram estimados por meio de análise das variáveis pelo modelo de regressão linear e quadrática.

\section{Resultados e Discussão}

A temperatura máxima obtida foi de $25,5 \pm 2,3{ }^{\circ} \mathrm{C}$ e a mínima de $18,5 \pm 3,1^{\circ} \mathrm{C}$. A Umidade relativa foi de $78,6 \pm 1,8 \%$.

Os níveis de fósforo disponível testados neste experimento não influenciaram $(\mathrm{P}>0,05)$ o consumo de ração, a produção de ovos ave-dia e ave-alojada, o peso e massa de ovo, a conversão alimentar nem a viabilidade (Tabela 2).

É importante ressaltar a necessidade das codornas em regular seu consumo quanto à ingestão do Pd dietético frente à relação desse mineral com o nível de cálcio e a produção de ovos. Em experimento conduzido por Costa et al. (2007), observou-se que aves que receberam dietas formuladas com o menor nível, 0,15\% de Pd, consumiram mais ração, porém sem diferença entre os tratamentos. Pedroso et al. (1999) também não encontraram diferenças significativas no consumo de ração. Entretanto, Garcia et al. (2000), estudando níveis de 0,27 a 0,42\% de Pd na dieta, observaram que o maior consumo ocorreu no nível de $0,36 \%$ de Pd.

Costa et al. (2007) e Pedroso et al. (1999) também não encontraram efeito significativo dos níveis de Pd da dieta

Tabela 2 - Desempenho de codornas japonesas alimentadas com dietas com diferentes níveis de fósforo disponível

\begin{tabular}{|c|c|c|c|c|c|c|c|}
\hline \multirow[t]{2}{*}{ Item } & \multicolumn{5}{|c|}{ Nível de fósforo disponível (\%) } & \multirow[t]{2}{*}{ Valor de $\mathrm{P}$} & \multirow[t]{2}{*}{ CV (\%) } \\
\hline & 0,15 & 0,25 & 0,35 & 0,45 & 0,55 & & \\
\hline Consumo de ração (g) & 25,42 & 28,10 & 26,02 & 25,38 & 26,61 & ns & 7,10 \\
\hline Ovos ave-alojada (\%) & 76,90 & 71,45 & 75,26 & 75,58 & 74,90 & ns & 8,93 \\
\hline Peso do ovo (g) & 12,07 & 12,29 & 12,19 & 11,93 & 12,22 & ns & 2,87 \\
\hline Massa de ovos (g) & 9,76 & 10,07 & 9,96 & 9,51 & 10,05 & ns & 10,29 \\
\hline Viabilidade (\%) & 91,67 & 80,00 & 90,00 & 91,67 & 88,33 & ns & 8,01 \\
\hline
\end{tabular}

ns = não-significativo $(\mathrm{P}>0,05)$.

$\mathrm{CV}=$ coeficiente de variação. 
sobre a produção de ovos/ave/dia, ao avaliarem, respectivamente, dietas contendo 0,15 a 0,55\% e 0,25 a $0,85 \%$ de Pd para codornas japonesas. No entanto, Garcia et al. (2000) observaram que o nível de 0,36\% de Pd proporcionou aumento na produção de ovos. Shirivastav \& Panda (1999) determinaram que o nível de 0,45\% de Pd proporcionou maior taxa de postura às aves. Há uma discrepância entre os resultados, sendo necessário avaliar a real relação dos níveis de cálcio e fósforo disponível estudados e o período produtivo avaliado, o que refletirá a idade das aves e a sua eficiência na absorção e disponibilização desses minerais para formação da casca e remodelação do tecido ósseo.

Neste experimento, como as aves já haviam ultrapassado o pico de produção, certamente a absorção intestinal e mobilização óssea foram menores em relação ao observado no início e pico de postura.

A menor deposição mineral na matriz óssea, devido à menor formação dos osteoblastos associada à reduzida função das proteínas transportadoras, exemplo vitamina D, envolvida na absorção de cálcio no intestino, e a redução do conteúdo de colágeno nos ossos são características comuns em aves em final de produção. Contudo, qualquer perda na densidade mineral dos ossos com a idade pode ser mascarada pelo aumento no componente medular, devido ao seu uso reduzido na calcificação da casca dos ovos, em função do decréscimo na taxa de postura, que ocorre com a idade. Dessa forma, aves idosas possuem menor capacidade de absorção intestinal e de mobilização óssea.

Não houve influência dos níveis de fósforo disponível sobre a viabilidade e produção média de ovos por ave alojada, o que está de acordo com os achados por Costa et al. (2007). Segundo esses autores, a mortalidade acumulada durante todo o experimento (84 dias) correspondeu a apenas $2,86 \%(0,24 \%$ por semana), porém, neste experimento, a mortalidade atingiu 11,7\% (0,97\% por semana), isso em decorrência do avanço da idade das aves. Dessa forma, é notório saber que, em granjas comerciais, a mortalidade média semanal de codornas japonesas é correspondente a 0,58\% (Murakami \& Ariki, 1998).

Não houve influência dos níveis de fósforo disponível sobre o peso médio dos ovos, porém o nível de 0,25\% de Pd favoreceu a produção de ovos de maior peso quando comparados aos produzidos pelas aves dos demais tratamentos. Este achado corrobora aquele obtido por Costa et al. (2007), que citam que os níveis de Pd variando de 0,15 a $0,55 \%$ na ração de codornas japonesas na fase inicial de postura, também não influenciaram o peso médio dos ovos. O mesmo foi encontrado por Pedroso et al. (1999), que, utilizando níveis de $0,25 \%$ a $0,85 \%$ de $\mathrm{Pd}$ na dieta das codornas, não notaram influência significativa do Pd sobre o peso médio dos ovos. Dessa forma, considerando estes dois trabalhos, pode-se inferir que o intervalo de 0,15\% até 0,85\% de Pd não exerce influência sobre o peso dos ovos, o que demonstra que a variável em questão é muito pouco influenciada pelo fósforo da dieta para sua maximização ou minimização.

Não houve diferença entre os níveis de Pd para massa de ovos e conversão alimentar por massa de ovos, semelhante a Costa et al. (2007). Diferentemente dos resultados encontrados acima, Garcia et al. (2000), relatam que o nível de $0,36 \%$ de $\mathrm{Pd}$ é suficiente para otimizar a conversão alimentar (kg/kg).

A necessidade de fósforo varia com a idade. Além disso, tanto a deficiência como o excesso de fósforo têm efeito prejudicial sobre a qualidade da casca do ovo, o que pode ser minimizado pela redução nos seus níveis dietéticos, aumentando a mobilização óssea do cálcio e/ou ativando a hidroxilação da vitamina D.

Com o avançar da idade das aves, é necessário reduzir a proteína e o fósforo da dieta e aumentar seu teor de cálcio, pois as aves diminuem a produção e a massa de ovos, e ocorre aumento do número de ovos inviáveis em final de produção para comercialização.

A conversão por dúzia não foi influenciada pelos níveis de fósforo disponível avaliados. Diferentemente, Costa et al. (2007) observaram efeito significativo dos níveis de Pd sobre a conversão alimentar por dúzia de ovos em codornas japonesas, onde $0,55 \%$ de Pd foi o nível que proporcionou a melhor conversão. Também, Garcia et al. (2000) observaram melhoria linear na conversão alimentar $(\mathrm{kg} / \mathrm{dz})$ com o aumento dos níveis de Pd da dieta.

Como os diferentes níveis de $\mathrm{Pd}$ estudados não influenciaram a produção de ovos, a massa de ovos também não foi influenciada (Tabela 3). Entretanto, apesar de não ter havido diferença estatística na produção de ovos viáveis ave-dia, o nível que maximizou o peso específico dos ovos foi correspondente a $0,43 \%$ de Pd contido na dieta.

Os níveis de fósforo disponível não influenciaram a produção de ovos viáveis para comercialização e viáveis ave-dia. Entretanto, houve melhoria da qualidade dos ovos, com efeito quadrático e maximização, respectivamente, do peso específico, do peso de casca, da porcentagem de casca e do teor de cálcio na casca dos ovos nos níveis de 0,43; 0,41; 0,42 e 0,27\% de Pd da dieta (Tabela 4).

Seria interessante destacar que aves mais velhas tendem a aumentar o índice de ovos com casca fraca (Tabela 5) quando expostas aos menores valores de fósforo disponível das dietas, uma vez que o metabolismo mineral fica prejudicado (Tabela 5). 
Tabela 3 - Qualidade dos ovos de codornas japonesas alimentadas com dietas com diferentes níveis de fósforo disponível

\begin{tabular}{|c|c|c|c|c|c|c|c|}
\hline Item & \multicolumn{5}{|c|}{ Nível de fósforo disponível (\%) } & Valor de $\mathrm{P}$ & CV $(\%)$ \\
\hline Ovos viáveis comerciais (\%) & 95,77 & 96,12 & 96,62 & 96,26 & 96,92 & ns & 2,30 \\
\hline Peso específico $\left(\mathrm{g} / \mathrm{cm}^{3}\right)$ & 1,0671 & 1,0685 & 1,0654 & 1,0685 & 1,0690 & $\mathrm{P}<0,05^{* *}$ & 0,10 \\
\hline Peso de casca (g) & 0,907 & 0,947 & 0,962 & 0,943 & 0,951 & $\mathrm{P}<0,05^{* *}$ & 2,73 \\
\hline Casca (\%) & 7,43 & 7,67 & 7,77 & 7,68 & 7,73 & $\mathrm{P}<0,05^{* *}$ & 2,25 \\
\hline Peso de gema (g) & 3,69 & 3,75 & 3,79 & 3,75 & 3,76 & ns & 2,10 \\
\hline Gema (\%) & 30,24 & 30,38 & 30,57 & 30,42 & 30,54 & ns & 1,90 \\
\hline Ca na casca (\%) & 34,26 & 35,06 & 35,54 & 32,44 & 30,51 & $\mathrm{P}<0,01^{* *}$ & 4,78 \\
\hline P na casca $(\%)$ & 0,299 & 0,320 & 0,296 & 0,310 & 0,296 & ns & 6,26 \\
\hline Mg na casca (\%) & 0,617 & 0,611 & 0,605 & 0,596 & 0,609 & ns & 6,96 \\
\hline Cinzas na Casca (\%) & 88,11 & 89,21 & 89,43 & 87,56 & 87,87 & ns & 1,52 \\
\hline
\end{tabular}

* Efeito linear; ** Efeito quadrático.

ns = não-significativo $(\mathrm{P}>0,05)$.

$\mathrm{CV}=$ coeficiente de variação.

Tabela 4 - Equações de regressão estimadas para os valores de qualidade dos ovos (Y) em função do nível de suplementação de fósforo (X) à dieta

\begin{tabular}{|c|c|c|c|}
\hline Variável & Equação & $\mathrm{R}^{2}$ & Nível ótimo \\
\hline Peso específico $\left(\mathrm{g} / \mathrm{cm}^{3}\right)$ & $\hat{Y}=1,06456+0,0214255 X-0,0249417 X^{2}$ & 0,81 & $0,43 \%$ \\
\hline Peso de casca (g) & $\hat{Y}=0,841421+0,570245 X-0,694139 X^{2}$ & 0,80 & $0,41 \%$ \\
\hline Casca $(\%)$ & $\hat{Y}=7,02294+3,46936 X-4,08524 X^{2}$ & 0,85 & $0,42 \%$ \\
\hline Cálcio na casca (\%) & $\hat{Y}=30,4784+35,1100 X-64,6155 X^{2}$ & 0,93 & $0,27 \%$ \\
\hline Altura do ovo (mm) & $\hat{Y}=33,1740+0,929449 X$ & 0,86 & - \\
\hline
\end{tabular}

Tabela 5 - Valores médios da produção de ovos com casca fraca e sem casca (em unidade)

\begin{tabular}{lccccc}
\hline Variável & \multicolumn{3}{c}{ Nível de fósforo disponível (\%) } \\
\cline { 2 - 5 } & 0,15 & 0,25 & 0,35 & 0,45 & 0,55 \\
\hline Casca fraca $^{1}$ & 13,50 & 9,67 & 8,17 & 11,83 & 8,83 \\
Sem casca $^{2}$ & 13,00 & 12,67 & 13,33 & 11,67 & 52,00 \\
Total & 26,50 & 22,34 & 21,50 & 23,50 & 10,67 \\
Catal & & & 19,50 & 13,34 \\
\hline
\end{tabular}

${ }^{1}$ Casca frágil e/ou mole.

${ }^{2}$ Com apenas a membrana da casca.

A maior produção de ovos com casca fraca ocorreu quando houve a inclusão do menor nível de fósforo disponível na dieta $(0,15 \%)$, correspondendo respectivamente a 28,4 ; 39,$5 ; 12,4$ e $34,6 \%$ a mais de ovos com esse tipo de defeito em relação aos valores obtidos nos demais níveis crescentes de Pd na dieta. Aves que receberam o menor nível testado, juntamente com aquelas que consumiram rações contendo 0,35\% de Pd na dieta, também apresentaram maior percentual de ovos sem casca. No entanto, como não houve efeito $(\mathrm{P}>0,05)$ dos diferentes níveis de Pd estudados sobre a produção de ovos viáveis para comercialização e viáveis ave-dia (Tabela 3), não se pode excluir a possibilidade do emprego desses níveis como recomendação para essas aves na fase de produção estudada.
Com a análise dos dados obtidos pela variável ovo viável ave-dia (\%), percebeu-se que ela está altamente correlacionada ao peso específico dos ovos, uma vez que as médias obtidas em ambas as variáveis permitem compreender melhor a influência dos níveis de Pd avaliados sobre a qualidade da casca dos ovos (Tabela 3).

Diferentemente do obtido neste experimento, Costa et al. (2007) observaram efeito dos níveis de Pd sobre a produção de ovos viáveis para comercialização e indicaram o nível de 0,31\% de Pd como satisfatório em atender essa variável.

Para o peso e a porcentagem de albúmem e de gema, não se observou efeito significativo dos níveis estudados; porém, os níveis de 0,15 e 0,35\% de Pd na dieta foram, 
respectivamente, responsáveis pelo aumento na porcentagem do albúmem e da gema. Esses resultados corroboram, em parte, os achados de Costa et al. (2007). Esses pesquisadores também não encontraram influência dos níveis citados sobre o peso e a percentagem de albúmem dos ovos. Entretanto, citam em suas pesquisas que houve diferença estatística entre os tratamentos para o peso e a percentagem de gema dos ovos.

As deposições de fósforo e magnésio na casca dos ovos não foram influenciadas pelos níveis de Pd, porém houve efeito quadrático $(\mathrm{P}<0,01)$ sobre a deposição de Ca, comprovando que o nível que favorece a maior mobilização desse mineral para a casca é equivalente a 0,27\% Pd. Apesar de os teores de $\mathrm{P}$ e de $\mathrm{Mg}$ na casca não terem sido influenciados, pode-se observar na Tabela 3, que o nível de $0,25 \%$ proporcionou a maior deposição de $\mathrm{P}(0,32 \%)$ e o nível de $0,15 \%$ a maior deposição de $\operatorname{Mg}(0,62 \%)$. Segundo Hamilton \& Sibbald (1997), a redução do nível de fósforo dietético com o avanço da idade das aves melhora a qualidade da casca do ovo. Roland \& Harms (1976) e Mongin \& Sauveur (1979) acreditam que as poedeiras utilizam melhor o cálcio reabsorvido dos ossos trazendo o fósforo juntamente com o cálcio quando baixos níveis dietéticos de fósforo são utilizados.

À medida que os níveis de fósforo disponível na dieta foram elevados, as aves aumentaram a deposição mineral na casca dos ovos produzidos até o nível de $0,35 \%$ Pd (89,43\% de cinzas). Níveis superiores a este promoveram redução na deposição de minerais na casca, que reduziu a índices percentuais inferiores aos obtidos com o menor nível estudado $(0,15 \%$ Pd $)$.

A altura dos ovos foi influenciada linearmente pelos níveis de Pd da dieta e isso indica que níveis equivalentes a $0,15 \%$ contribuem para a produção de ovos de maior tamanho. Não se observou efeito no diâmetro dos ovos. De acordo com Costa et al (2007), os níveis de Pd influenciaram de forma quadrática a altura e o diâmetro médio dos ovos; os valores de 0,29 e $0,27 \%$ de Pd foram os que maximizaram as duas características, respectivamente. O tamanho do ovo está diretamente relacionado ao seu peso e à idade das aves, no entanto, o peso médio dos ovos não variou entre os níveis de fósforo consumido e percebeu-se que a exigência em Pd pelas aves para produzir ovos mais alongados ou de maior diâmetro aumentou com o avanço da idade.

A absorção intestinal de fósforo nos monogástricos se dá por um mecanismo ativo e saturável, que é influenciado pela presença de íons sódio no lume intestinal e estimulado pela vitamina $\mathrm{D}$. O fosfato, na sua forma mais simples, a de $\mathrm{PO}_{4}{ }^{-3}$ (ortofosfato), é bem absorvido e utilizado pela ave, no entanto, quando essas moléculas se unem formando polifosfatos, a absorção pela parede intestinal é muito baixa e pouco ou nenhum fósforo é retido (Tabela 2).

Apesar de o fósforo ser importante na formação do ovo e casca, é um dos elementos mais excretados ao meio ambiente. Dessa forma, preconiza-se o uso da enzima fitase, pois proporciona a liberação do fósforo fítico presente nos alimentos, havendo menor necessidade de suprir a ração com fontes de fósforo inorgânico, diminuindo custos e poluição ambiental.

Foi realizada a avaliação dos teores percentuais de Ca, P, Mg e cinzas na tíbia e na excreta das codornas japonesas (Tabela 6). Na análise dos teores de minerais na excreta das aves, verificou-se efeito quadrático nos teores de fósforo, cálcio e de cinzas nas excretas, com pontos de máxima deposição nos níveis de 0,43; 0,34 e 0,30\% Pd (Tabela 7). Contudo, não se observou efeito sobre a excreção de magnésio.

Com o aumento dos níveis de fósforo disponível da dieta, houve maior deposição de magnésio e cálcio na tíbia das aves. Entretanto, para o teor de fósforo na tíbia, essa maximização ocorreu no nível de $0,42 \%$ de Pd, indicando efeito quadrático para essa variável. No entanto, com o

Tabela 6 - Teores de cálcio, fósforo, magnésio e cinzas na tíbia e nas excretas de codornas japonesas alimentadas com dietas com diferentes níveis de fósforo disponível

\begin{tabular}{|c|c|c|c|c|c|c|c|}
\hline \multirow[t]{2}{*}{ Item } & \multicolumn{5}{|c|}{ Nível de fósforo disponível (\%) } & \multirow[t]{2}{*}{ Valor de $\mathrm{P}$} & \multirow[t]{2}{*}{ CV (\%) } \\
\hline & 0,15 & 0,25 & 0,35 & 0,45 & 0,55 & & \\
\hline Cálcio no osso (\%) & 23,06 & 25,23 & 25,23 & 25,51 & 25,38 & $\mathrm{P}<0,05^{*}$ & 6,51 \\
\hline Fósforo no osso (\%) & 9,18 & 10,55 & 10,21 & 10,64 & 10,40 & $\mathrm{P}<0,01 * *$ & 3,66 \\
\hline Magnésio no osso (\%) & 0,347 & 0,386 & 0,411 & 0,395 & 0,417 & $\mathrm{P}<0,01 *$ & 7,02 \\
\hline Cálcio excretado (\%) & 6,25 & 6,60 & 6,87 & 6,69 & 5,98 & $\mathrm{P}<0,05 * *$ & 9,80 \\
\hline Fósforo excretado (\%) & 0,89 & 1,20 & 1,48 & 1,81 & 1,39 & $\mathrm{P}<0,01 * *$ & 7,72 \\
\hline Magnésio excretado (\%) & 0,439 & 0,437 & 0,443 & 0,439 & 0,452 & ns & 5,03 \\
\hline Cinza óssea (\%) & 61,52 & 65,60 & 66,69 & 63,23 & 65,90 & ns & 4,78 \\
\hline Cinza excretado (\%) & 25,22 & 25,54 & 25,55 & 25,66 & 22,34 & $\mathrm{P}<0,01 * *$ & 4,90 \\
\hline
\end{tabular}

* Efeito linear.

** Efeito quadrático.

ns = não-significativo $(\mathrm{P}>0,05)$

$\mathrm{CV}=$ coeficiente de variação. 
Tabela 7 - Equações de regressão estimadas para os valores obtidos durante o ensaio de metabolismo (Y) em função do nível de suplementação de fósforo $(\mathrm{X})$ à dieta

\begin{tabular}{llcc}
\hline Variável & \multicolumn{1}{c}{ Equação } & $\mathrm{R}^{2}$ & Nível ótimo \\
\hline Ca no osso (\%) & $\hat{Y}=23,1570+4,92167 \mathrm{X}$ & 0,57 & - \\
P no osso (\%) & $\hat{Y}=7,50594+14,8484 X-17,5858 X^{2}$ & 0,77 & $0,42 \%$ \\
Mg no osso (\%) & $\hat{Y}=0,338600+0,150000 X$ & 0,73 & - \\
Ca excretado (\%) & $\hat{Y}=4,76261+12,3513 X-18,2988 X^{2}$ & 0,96 & 0,86 \\
P excretado (\%) & $\hat{Y}=-0,246365+8,68463 X-10,0893 X^{2}$ & $0,34 \%$ \\
Cinza na excreta (\%) & $\hat{Y}=21,5640+30,3437 X-51,3920 X^{2}$ & $0,43 \%$ \\
\hline
\end{tabular}

cálculo da relação Ca:P no tecido ósseo, percebeu-se que a mesma manteve-se entre 2,4:1 e 2,5:1 para os níveis de $\mathrm{Pd}$ testados, comprovando a capacidade dessas aves de regular a homeostase óssea, dos minerais cálcio e fósforo, por meio da atuação dos hormônios calcitonina e paratormônio durante a fase de postura, não se esquecendo também da importância da vitamina $\mathrm{D}_{3}$ nessa regulação, uma vez que, no caso de deficiência dessa vitamina ou de seus metabólitos ativos, a primeira ocorrência é a hipofosfatemia e elevação da fosfatase alcalina.

Esses resultados discordam dos relatos de Costa et al. (2007), de que o nível de 0,46\% de Pd na dieta é suficiente para proporcionar maior percentagem de cálcio no tecido ósseo, de Garcia et al. (2000), Abdallah et al. (1993) e Keshavarz \& Nakajima (1993) de que os níveis de fósforo disponível não influenciam a porcentagem de cálcio nos ossos.

Diferentemente dos resultados obtidos, Costa et al. (2007), trabalhando com dietas formuladas com 2,5\% de cálcio, verificaram aumento na deposição de fósforo no tecido ósseo das aves à medida que aumentaram o nível de fósforo disponível da dieta; entretanto, esse aumento ocorreu no nível de 0,51\% de Pd, no qual atingiu-se um platô. Quando se utilizaram dietas contendo 3,2\% de cálcio, esses mesmos pesquisadores observaram que os níveis de fósforo disponível tiveram efeito quadrático sobre o teor de fósforo nos ossos, evidenciando que o nível de 0,32\% de Pd reduziu o teor de fósforo nos ossos.

Resultados semelhantes foram encontrados por Garcia et al. (2000), que também notaram efeito quadrático em experimento com codornas em postura. Esses autores observaram que os níveis de $\mathrm{Pd}$ na ração também influenciaram de forma quadrática a porcentagem de fósforo nos ossos e que essa porcentagem foi maior no nível de 0,35\% de Pd na ração, resultado um pouco inferior ao obtido neste experimento $(0,42 \%$ de $\mathrm{Pd})$.

O nível de $0,15 \%$ de Pd proporcionou a menor deposição de magnésio no osso, porém não houve comprometimento no desempenho das aves (91,7\% de viabilidade) (Tabela 2$)$. Observou-se também que não houve diferença significativa entre os níveis de Pd testados sobre a produção de ovos viáveis para comercialização e que, no nível de $0,15 \%$ de Pd, houve menor excreção de fósforo e redução da excreção de cálcio, obtendo-se relação Ca:P no material excretado de 7:1, a maior obtida entre os tratamentos. Além disso, como não houve efeito dos níveis testados sobre a deposição de fósforo, magnésio e cinzas na casca do ovo (Tabela 4) e, como o nível de $0,15 \%$ de Pd satisfez todas as variáveis de desempenho analisadas e o fósforo é o mineral que mais onera o custo da ração, o nível de $0,15 \%$ de $\mathrm{Pd}$ pode ser considerado satisfatório em dietas para codornas japonesas no terço final do ciclo de produção.

\section{Conclusões}

O nível de 0,15\% de fósforo disponível, correspondente ao consumo diário de $38 \mathrm{mg}$ de fósforo disponível por ave, é suficiente para obtenção de desempenho satisfatório e manutenção da integridade física do ovo, embora promova redução na mineralização da casca e do tecido ósseo de codornas japonesas, sem comprometimento de ambos, no terço final do ciclo de produção (45 a 57 semanas de idade).

\section{Referências}

ABDALLAH, A.G.; HARMS, R.H.; HUSSEINY, O. Performance of laying eggs whit heavy or light shell weight when fed diets whit different calcium and phosphorus levels. Poultry Science, v.72, n.10, p.1881-1891, 1993.

COSTA, C.H.R.; BARRETO, S.L.; MOURA, W.C.O. et al. Níveis de fósforo e cálcio em dietas para codornas japonesas em postura. Revista Brasileira de Zootecnia, v.36, n.6, p.2037-2046, 2007 (supl.).

GARCIA, J.; MURAKAMI, A.E.; MARTINS, E.N. et al. Exigências nutricionais de cálcio e fósforo para codornas japonesas (Coturnix coturnix japonica) em postura. Acta Scientiarum, v.22, n.3, p.733-739, 2000.

HAMILTON, R.M.G. Methods and factors that affect the measurement of egg shell quality. Poultry Science, v.61, p.2022-2039, 1982.

HAMILTON, R.M.G.; SIBBALD, I.R. The effects of dietary phosphorus on productive performance and egg quality of ten strains of white leghorns. Poultry Science, v.56, n.4, p.1221-1228, 1997.

KESHAVARZ, K.; NAKAJIMA, S. Re-evaluation of phosphorus requirements of laying hens for optium performance and eggshell quality. Poultry Science, v.72, p.114-153, 1993.

MONGIN, P.; SAUVEUR, G. Plasma inorganic phosphorus concentration during eggshell formation. British Poultry Science, v.20, n.4, p.401-412, 1979. 
MURAKAMI, A.E.; ARIKI, J. Produção de codornas japonesas. Jaboticabal, 1998. 79p.

NATIONAL RESEARCH COUNCIL - NRC. Nutrient requirements of poultry. 9.ed. Washington: National Academy of Sciences, 1994. 155p.

OLIVEIRA, B.L. Manejo em granjas automatizadas de codornas de postura comercial. In: SIMPÓSIO INTERNACIONAL DE COTURniCulturA, 3., 2007, Lavras. Anais... Lavras: Universidade Federal de Lavras, 2007.

PEDROSO, A.; MORAES, V.M.B.; ARIKI, J. et al. Efeito de níveis dietéticos de cálcio e fósforo disponível sobre o desempenho e qualidade dos ovos de codornas japonesas. Ars Veterinária, v.15, n.2, p.135-139, 1999.

PINHEIRO, S.R.; BARRETO, S.L.T.; ALBINO, L.F.T. et al. Efeito dos níveis de triptofano digestível em dietas para codornas japonesas em postura. Revista Brasileira de Zootecnia, v.37, n.6, p.1012-1016, 2008.

PINTO, R.; FERREIRA, A.S.; DONZELE, J.L. et al. Exigência de metionina mais cistina para codornas japonesas em postura. Revista Brasileira de Zootecnia, v.32, n.5, p.1166-1173, 2003a.
PINTO, R.; FERREIRA, A.S.; DONZELE, J.L. et al. Exigência de lisina para codornas japonesas em postura. Revista Brasileira de Zootecnia, v.32, n.5, p.1182-1189, 2003b.

RECOMENDAÇÃO PARA A NUTRIÇÃO ANIMAL. 5.ed. France: Rhône Poulenc, 1987. 86p.

ROLAND, SR.D.A.; HARMS, R.H. The influence of feeding diets containing different calcium-phosphorus ratios on the laying hen. Poultry Science, v.55, n.2, p.637-641, 1976.

SHIRIVASTAV, A.K.; PANDA, B. A review of quail nutrition research in India. World's Journal Poultry Science, v.55, n.1, p.73-81, 1999.

SILVA, D.J. Análises de alimentos (métodos químicos e biológicos). Viçosa, MG: Imprensa Universitária, 1998. 166p.

UMIGI, R.T.; BARRETO, S.L.; DONZELE, J.L. et al. Níveis de treonina digestível em dietas para codorna japonesa em postura. Revista Brasileira de Zootecnia, v.36, n.6, p.1868-1874, 2007. UNIVERSIDADE FEDERAL DE VIÇOSA _ UFV. Central de Processamento de Dados (UFV/CPD). Manual de utilização do programa SAEG (Sistema para Análises Estatísticas e Genéticas). Viçosa, MG: UFV, 2004. 59p. 